\title{
Laboreal
}

Volume $7 \mathrm{~N}^{\circ} 1$ | 2011

Psicodinâmica e psicopatologia do trabalho

\section{Higiene Pública : estatística de acidentes de trabalho}

Higiene Pública : estadística de accidentes de trabajo

Hygiène Publique : statistique d'accidents de travail

Public health: work accidents' statistics

\section{Armand Imbert e Antonim Mestre}

Tradutor. João Viana Jorge

\section{OpenEdition}

\section{Journals}

\section{Edição electrónica}

URL: http://journals.openedition.org/laboreal/8458

DOI: 10.4000/laboreal.8458

ISSN: 1646-5237

\section{Editora}

Universidade do Porto

\section{Refêrencia eletrónica}

Armand Imbert e Antonim Mestre, « Higiene Pública : estatística de acidentes de trabalho », Laboreal

[Online], Volume $7 \mathrm{~N}^{0} 1$ | 2011, posto online no dia 01 julho 2012, consultado o 24 setembro 2020

URL : http://journals.openedition.org/laboreal/8458 ; DOI : https://doi.org/10.4000/laboreal.8458

Este documento foi criado de forma automática no dia 24 setembro 2020.

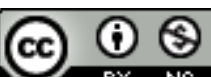

Laboreal está licenciado com uma Licença Creative Commons - Atribuição-NãoComercial 4.0 Internacional. 


\title{
Higiene Pública : estatística de acidentes de trabalho
}

\author{
Higiene Pública : estadística de accidentes de trabajo \\ Hygiène Publique : statistique d'accidents de travail \\ Public health: work accidents' statistics
}

Armand Imbert e Antonim Mestre

Tradução : João Viana Jorge

\section{REFERÊNCIA}

Artigo original : Imbert, A., \& Mestre, A. (1904). Hygiène Publique : statistique d'accidents de travail. Revue Scientifique, $\mathrm{n}^{\circ} 13$, Tome11 (p. 385-390).

1 É uma verdade, a ser difundida para além dos meios científicos, a de que os métodos e aparelhos de laboratório podem ajudar a resolver alguns dos mais agudos problemas existentes entre o capital e o trabalho. Por evidente que esta verdade o seja para aqueles que se têm preocupado com este género de utilização prática dos dados da ciência experimental, os próprios interessados, patrões e operários, nem dela suspeitam, e os esforços feitos para a divulgar constituem, cremos, uma obra essencialmente útil e proveitosa para o interesse geral.

De entre as questões que envolve o actual problema social e cuja solução imparcial pode assim ser procurada fora das discussões apaixonadas dos interessados, figuram, em particular, as da duração da jornada (de trabalho) e, mais genericamente, as da organização do trabalho [1].

3 Se a produção do trabalho é necessária para assegurar e conservar o bom funcionamento do motor animado que somos, é impeditivo, sob pena de deterioração do organismo, que o fornecimento de energia que temos de satisfazer ultrapasse determinados limites; é perigoso, além disso, tendo em vista o desenvolvimento completo desse organismo e o seu rendimento futuro, fazer uma utilização 
excessivamente precoce e intensiva; não é indiferente, por outro lado que para um mesmo número de horas de trabalho efectivo, que essas horas de ocupação profissional sejam consecutivas ou entrecortadas por um ou vários períodos de repouso.

Os efeitos nocivos de práticas que seriam desde logo condenáveis podem ser investigados por métodos diversos, dos quais alguns exigem pôr em prática técnicas de laboratório enquanto outros consistem simplesmente na interpretação de constatações feitas frequentemente com vista a outra finalidade.

5 No conjunto destas últimas deve incluir-se o estudo das estatísticas dos acidentes de trabalho declarados oficialmente por aplicação da lei de 9 de Abril de 1898 [2]. Por consistir, na aparência, num simples agrupamento de números, o método não deixa de ser verdadeiramente científico, ou, mais rigorosamente, fisiológico, em termos do seu princípio de base.

6 Com efeito, o trabalho engendra a fadiga, e esta traduz-se, em particular, por modificações que sobrevêm no modo de funcionamento do motor que trabalha, o músculo, e que consistem num abrandamento e numa diminuição da intensidade da contracção. Sem entrar no detalhe dos fenómenos, em rápida sucessão, que se manifestam num operário, a partir do momento em que ele é advertido de que um acontecimento súbito surgiu até que efectue os movimentos de defesa ou de recuo destinados a subtraí-lo ao perigo que o ameaça, digamos apenas que um operário está tanto menos apto a efectuar esses movimentos com a rapidez e a energia necessárias quanto mais notório o estado de fadiga que apresenta. Segue-se que o número de acidentes deve ser tanto maior quanto mais fatigados estão os operários e a distribuição desses acidentes segundo a hora da jornada de trabalho durante a qual se verificaram deve fornecer um meio para avaliar o grau de fadiga dos trabalhadores vitimados.

7 Tal método de observação é sem dúvida indirecto e estatísticas desse tipo apresentam sempre algumas incertezas; em contrapartida a distribuição dos acidentes pelas horas a que aconteceram implica a vantagem de fornecer informações referentes ao conjunto de operários. As particularidades individuais, o nível de treinamento mais ou menos perfeito, a maior ou menor resistência, etc, desaparecem, e os resultados representam uma média da qual se deduzirão indicações precisas sobre as modificações que podem ter de ser introduzidas na organização do trabalho de cada profissão.

8 Tais estatísticas foram talvez organizadas no estrangeiro; pelo menos encontramos-lhe alguns "traços" em diversos trabalhos sem todavia conseguir encontrar as próprias estatísticas. Pelo contrário não parece que se tenha ainda, em França, distribuído os acidentes pela hora de trabalho e as noções que decorrem deste modo de classificação não parecem habituais entre os principais interessados, operários, patrões e companhias de seguros. Pode todavia avaliar-se, pelo que segue, o interesse que apresenta o estudo dos dados numéricos que resultam da aplicação da lei de 9 de Abril de 1898 sobre os acidentes de trabalho.

9 Esta lei, entre outras prescrições, torna obrigatório, para certas profissões, a declaração de qualquer acidente que provoque uma incapacidade de trabalho de mais de quatro dias, e essas declarações são centralizadas, em cada departamento, nas mãos de um funcionário, o inspector departamental do trabalho. São estes documentos oficiais que utilizámos em primeiro lugar no departamento de Hérault que conta 56458 operários de diversas profissões submetidas àquela lei, os quais foram, no seu conjunto, vítimas de 2065 acidentes declarados. 
10 A curva, a traço contínuo, da fig.63 representa, distribuídos segundo a hora a que aconteceram, os 660 acidentes relativos às profissões qualificadas oficialmente como de Manutenção e Transportes que englobam 16695 operários. Decorrem imediatamente do exame desta curva as seguintes indicações gerais :

$111^{\text {o }}$ - O número de acidentes aumenta progressivamente de hora em hora durante a primeira metade da jornada de trabalho ;

$122^{\mathrm{o}}$ - Depois do repouso bastante longo do meio-dia, nas primeiras horas da segunda metade da jornada de trabalho o número de acidentes é notoriamente menor que na última hora da manhã ;

$133^{\text {o }}$ - No decurso da segunda metade da jornada de trabalho os acidentes tornam-se de novo progressivamente mais numerosos ;

$144^{\circ}$ - O número máximo de acidentes por hora, perto do fim da segunda metade da jornada de trabalho é notoriamente mais elevado que o correspondente máximo da manhã.

15 Não se poderia, ao que parece, desejar à priori uma mais rigorosa confirmação das deduções extraídas da influência que a fadiga dos operários exerce sobre o aparecimento de acidentes; importa todavia garantir em primeiro lugar que os acidentes ocasionados pelo exercício de outras profissões conduzem aos mesmos resultados.

Figura 63 - Indústrias químicas (tracejado) - 1453 operários, 326 acidentes Indústrias da madeira (ponteado) -4528 operários, 189 acidentes

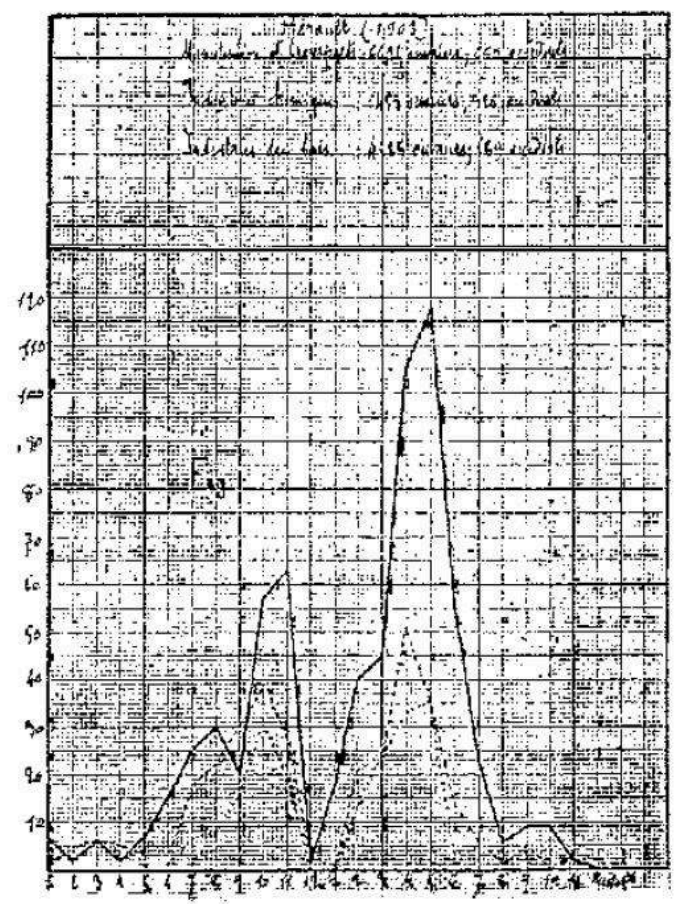

Figura 63

16 É o que mostram as curvas a tracejado e a ponteado da figura 63 bem como as da figura 64 que representam a distribuição horária dos acidentes ocorridos nas seguintes profissões : 
Figura 64 - Terraplanagens e construções em pedra (traço contínuo) : 4686 operários, 280 acidentes

Trabalho em metais comuns (tracejado) : 8237 operários, 149 acidentes

Comércio e banca (ponteado) : 15567 operários, 237 acidentes

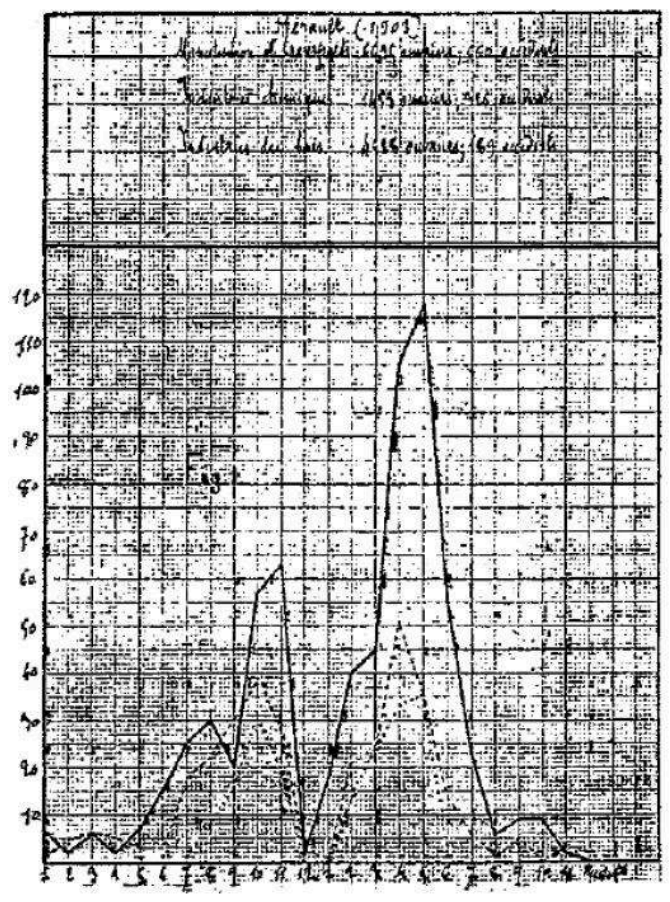

Figura 64

Comparando estas curvas umas com as outras notam-se algumas diferenças quanto às horas do máximo de acidentes. Mas há motivo para acreditar que essas diferenças são devidas, por um lado, a que essas estatísticas se referem a um ano inteiro, verão e inverno, e portanto a jornadas de durações variáveis com intervalos para repouso com diferente distribuição, e por outro lado, a que cada grupo engloba na realidade profissões diferentes para as quais as horas de trabalho e de repouso não são exactamente as mesmas.

18 O inspector da divisão residente em Toulouse, o senhor Leroy entendeu comunicar-nos os resultados de estatísticas análogas que espontaneamente se ofereceu para fazer implementar pelos inspectores departamentais sob as suas ordens (Aude, Ariège, Aveyron, Cantal, Haute-Garonne, Lozère, Pirénées Ocidentales, Tarn-et-Garonne). Sem reproduzir aqui as curvas que representam essas diversas estatísticas, diremos somente que todas, sem excepção, apresentam as características gerais que enunciamos acima.

Estas mesmas características devem então encontrar-se nas curvas globais relativas ao conjunto de todos os acidentes ocorridos nas diversas profissões. É o que mostra a figura 65 na qual a curva a traço contínuo representa, com distribuição horária, os 2065 acidentes de que foram vítimas os 56458 operários do departamento de Hérault e em que a curva a ponteado representa, numa outra escala, a distribuição horária dos 5534 acidentes que ocorreram com os 140467 operários dos nove departamentos da circunscrição de Toulouse. A menos que sérias críticas possam ser formuladas contra as estatísticas baseadas em documentos oficiais, a distribuição dos acidentes pelo horário 
de trabalho a que se produzem mostra bem a influência crescente da fadiga, do início ao fim de cada meia jornada de trabalho com o máximo mais acentuado à tarde.

Ora as únicas críticas a formular parecem-nos ser as seguintes :

a. É de temer, e sabemos que algumas vezes assim foi, que nem todos os acidentes sejam declarados, caso em que os números acima citados e as curvas que deles deduzimos não corresponderiam à realidade. Mas pode considerar-se, a este respeito, que essas omissões talvez bastante numerosas no início da aplicação da lei de 1898, devem ser agora cada vez mais raras. Ora as nossas estatísticas dizem respeito ao ano de 1903 e aliás, as omissões, se as há, não podem referir-se a uma hora especial e infirmar assim os resultados gerais verificados. Estes, salvo outras objecções, podem portanto ser considerados como adquiridos com o grau aproximado de exactidão que se pode esperar atingir em apreciações semelhantes.

b. A crítica que se segue, inicialmente parece mais grave. Se a fadiga é uma causa de acidentes, o seu nível não o é menos, geralmente proporcional à gravidade deste, porque essa gravidade, ela própria, depende de circunstâncias completamente fortuitas. Ora a lei não exige senão a declaração de acidentes que tenham implicado uma incapacidade de trabalho com a duração de pelo menos quatro dias. Em consequência um bom número de acidentes que possam ser devidos à fadiga escapam à declaração legal e não estão incluídos nas nossas estatísticas que assim se encontrariam falseadas.

Aqueles dos acidentes ligeiros, não submetidos à declaração legal, que não são devidos à fadiga, devem, como os acidentes não declarados, e para estatísticas incidindo em números de alguma relevância, distribuir-se de modo aproximadamente uniforme pelas diversas horas da jornada de trabalho, o que em nada altera a forma geral das curvas das figuras precedentes nem as consequências que deduzimos dessas formas. Por outro lado, se um certo número de acidentes, não submetidos a declaração em consequência da sua pequena gravidade, são apesar de tudo devidos à fadiga, devem ser mais numerosos nas últimas horas de cada meia jornada e trabalho e a sua introdução nas estatísticas acentuaria desde logo as características gerais das curvas das figuras 63, 64 e 65 .

Pode portanto concluir-se que as nossas estatísticas dos acidentes referidos à hora de trabalho à qual ocorrem mostram claramente a influência que a fadiga profissional exerce, com o nosso modo de organização do trabalho, sobre a ocorrência de acidentes.

Feita esta constatação que pode dela concluir-se ? Porque, sobretudo em assuntos deste tipo, o valor de um facto é tanto maior quanto mais consequências práticas dele se puderem retirar.

Ora dado que a fadiga é a consequência inevitável de qualquer dispêndio de energia, que não se pode portanto suprimi-la sem suprimir ao mesmo tempo todo e qualquer trabalho, seria pelo menos necessário impedir que atingisse o grau a partir do qual a sua influência no ocorrer dos acidentes é sobretudo nefasta. 
Figura 65

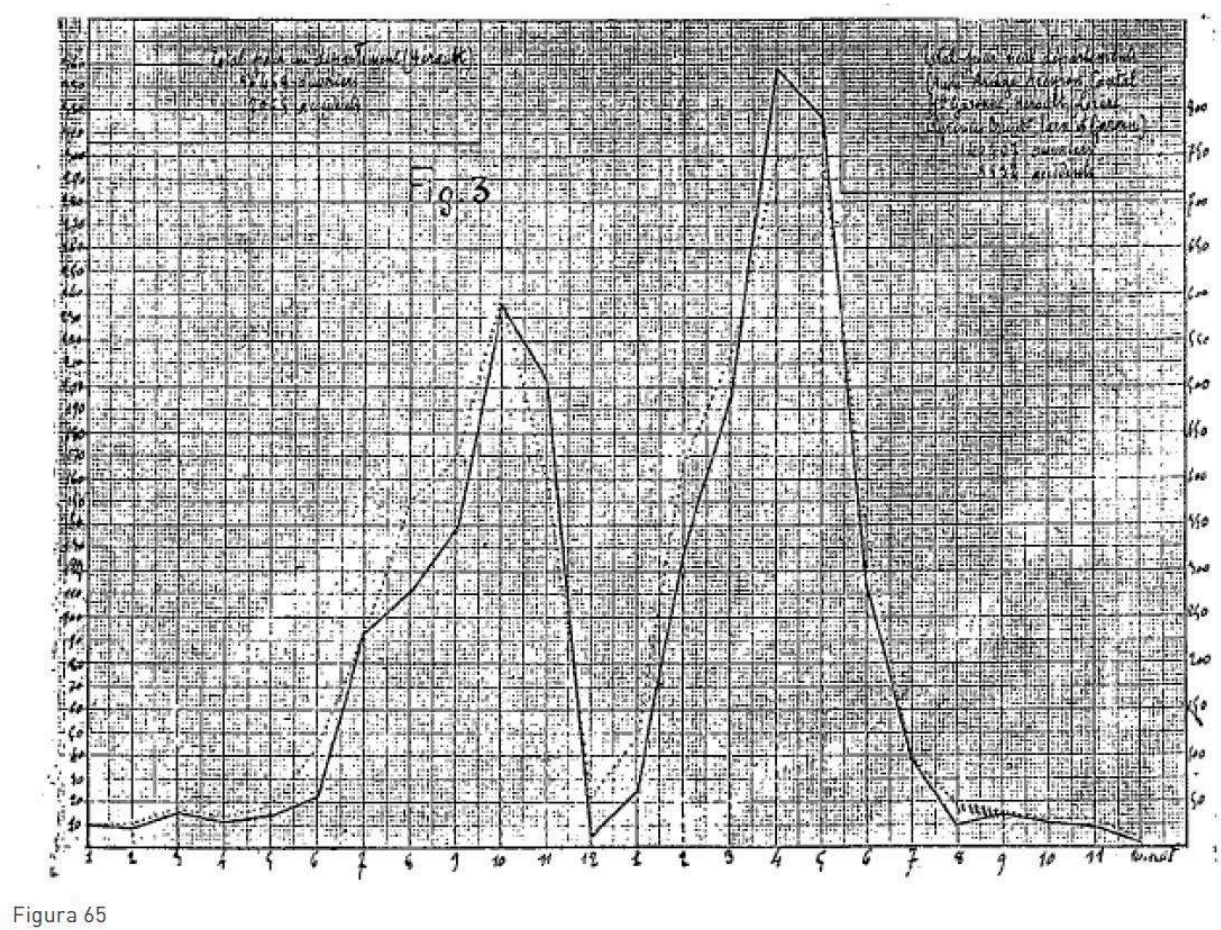

Se nos reportamos ao que temos constatado durante as primeiras horas da retoma do trabalho da parte da tarde parece que seria suficiente, para determinar uma notória diminuição do número de acidentes, intercalar a meio de cada uma das duas partes da jornada de trabalho um período de repouso, evidentemente menor que o do meio-dia, porque a fadiga seria então menor, com uma duração a determinar segundo as diversas considerações a ter em conta em semelhantes matérias. Ao editar tais prescrições mais não se faria do que aplicar ao trabalho mecânico e a adultos as medidas que há longo tempo foram postas em prática com as crianças no que diz respeito ao trabalho intelectual.

Estatísticas análogas àquelas de que demos a conhecer os resultados mas nas quais os acidentes seriam agrupados segundo o dia da semana mostrariam na mesma se o repouso dominical é suficiente para fazer desaparecer todos os traços da fadiga semanal ou se haveria justificação fisiológica para aumentar a duração desse repouso. Ocupamo-nos a estabelecer estatísticas semelhantes para um certo número de departamentos do sul e daremos, ulteriormente, conhecimento das consequências. Podemos, pelo menos, acrescentar desde já, que tendo encontrado no Bulletin du Travail de Belgique os acidentes agrupados por dia da semana, a comparação dos números não acusa nenhum aumento de segunda a sábado. Mas esta é uma questão que nos propomos retomar.

Os dados oficiais que resultam da aplicação da lei de 9 de Abril de 1898 permitem avançar ainda outras constatações interessantes.

Qualquer declaração de acidente comporta a indicação sumária das condições nas quais ocorreu o acidente e a seguir da causa a que é devido. Torna-se então fácil agrupar esses acidentes segundo as suas causas, o que conduz a resultados que também podem ser representados graficamente como fizemos nas figuras 66, 67 e 68 para as profissões 
oficialmente qualificadas : Manutenção e Transportes, Indústrias da Madeira, Terraplanagens e Construções em Pedra. Resulta, do exame destas figuras, que existe, para cada profissão, uma espécie de acidente tipo, característico do género de trabalho próprio dessa profissão, e por isso causa da frequência máxima de acidentes.

Figura 66

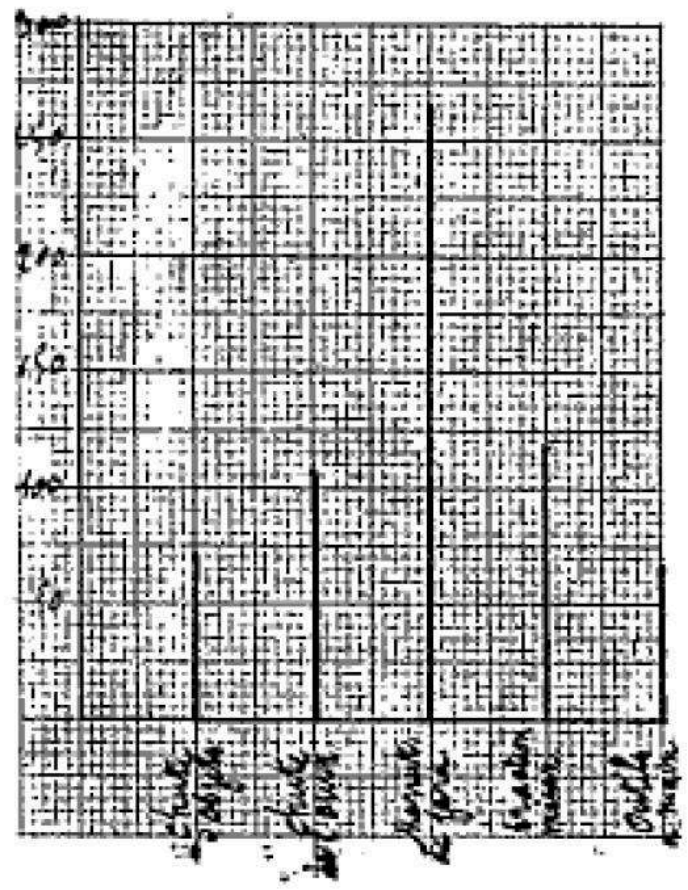

Figura 66

30 A importância de uma tal noção é evidente. Se se pretende de facto tentar reduzir o número de acidentes suprimindo outras causas que não a fadiga, conhece-se assim, para cada profissão, qual a via em que o esforço e a vigilância, a do inspector do trabalho em particular, devem mais especificamente incidir.

31 É ainda possível, considerando a relação do número $N$ de operários de uma profissão e o número $n$ dos que de entre eles foram vítimas de um acidente, avaliar o risco médio que o exercício dessa profissão acarreta. Eis, a título de indicação os resultados fornecidos, para o departamento de Hérault, pelo cálculo da relação que acabamos de definir.

\begin{tabular}{|l|l|}
\hline Profissões & Relação N/n \\
\hline Manutenção e transportes & 10,14 \\
\hline Indústrias químicas & 4,15 \\
\hline Indústrias da madeira & 23,95 \\
\hline Terraplanagens e construções em pedra & 16,73 \\
\hline Comércio, banca & 236,45 \\
\hline
\end{tabular}


Figura 67

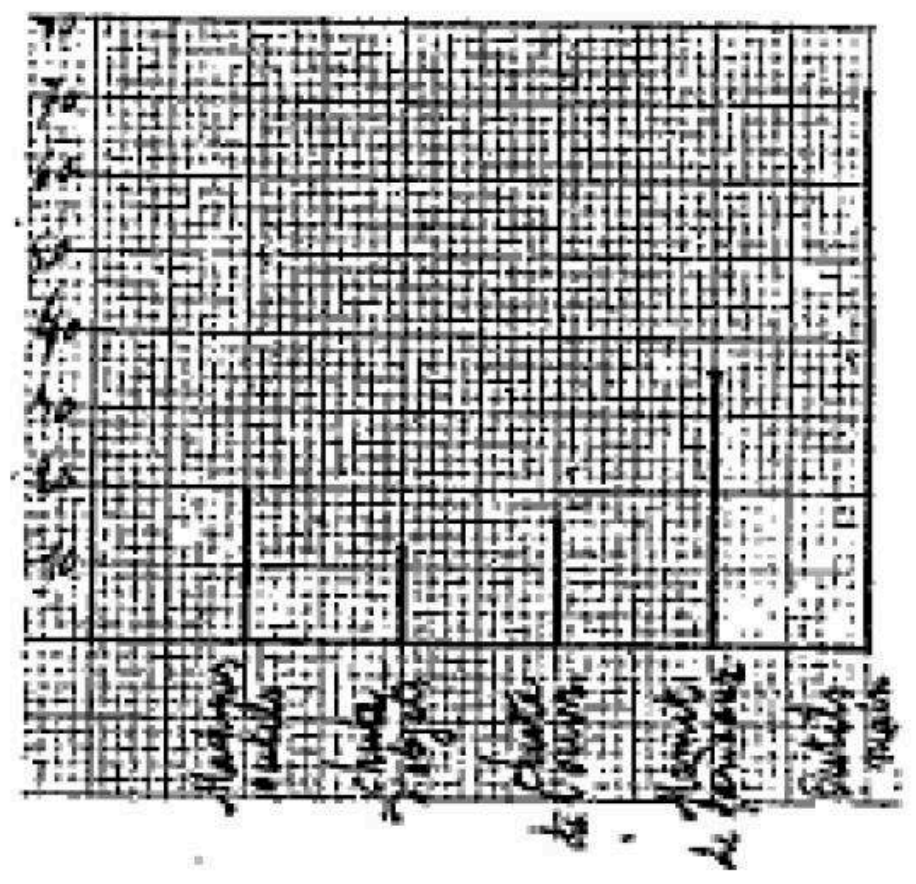

Figura 67

As profissões mais perigosas são portanto as incluídas na rubrica Indústrias químicas; imediatamente a seguir vêm Manutenção e Transportes, etc. Há, sem dúvida, algumas reservas a incidir sobre a exactidão absoluta destes resultados, as Indústrias químicas, por exemplo, não empregariam no departamento de Hérault mais do que 1458 operários, número relativamente pouco elevado ; os valores numéricos da relação $\mathrm{N} / \mathrm{n}$ da tabela precedente não estarão, todavia, muito afastados da realidade e não se pode senão ser dolorosamente impressionado pelas constatações de que em cerca de cinco anos, nas Indústrias químicas, e em dez ou onze anos na Manutenção e Transportes, todos os operários são sucessivamente vítimas de acidentes, a menos que, conforme o adágio bis repetita ... ainda que este adágio não tenha sido formulado para os acidentes de trabalho, um certo número de entre eles seja atingido várias vezes.

33 É ainda interessante fazer uma outra constatação, a que diz respeito, em cada profissão, à importância relativa do acidente tipo, importância que pode avaliar-se calculando a relação $n^{\prime} \times 100 / n$ representando $n^{\prime}$ o número de acidentes tipo e $n$ o número total de acidentes devidos a qualquer causa.

o cálculo conduz aos seguintes resultados

\begin{tabular}{|l|l|}
\hline Profissões & n'x100/n \\
\hline Manutenção e Transportes & 39,7 \\
\hline
\end{tabular}




\begin{tabular}{|l|l|}
\hline Indústrias químicas & 22,1 \\
\hline Indústrias da madeira & 38 \\
\hline Terraplanagens e Construções em pedra & 29,2 \\
\hline Comércio, banca & 33,2 \\
\hline
\end{tabular}

Resulta destes números que, se as diversas profissões são muito desigualmente perigosas como mostram os números de uma tabela precedente, a importância do acidente tipo, para cada uma delas, oscila somente entre, aproximadamente 1/5 e 1/3.

Terminando aqui o nosso estudo estatístico, não cremos ter extraído, dos dados oficiais resultantes da aplicação da lei de 9 de Abril de 1898, tudo o que esses dados poderiam fornecer, como nos propomos comprovar posteriormente. Só pretendemos mostrar, com alguns exemplos, quão importantes são as noções que se podem extrair dos documentos oficiais relativos a acidentes de trabalho e qual o interesse que apresenta, para os interessados, operários e Companhias de seguros, bem como para o legislador, a utilização destas noções a fim de levar a bom termo um projecto que está ainda longe de conduzir aos resultados que se podem razoavelmente propor alcançar.

\section{NOTAS}

1. A. IMBERT. Les accidents du travail et les Compagnies d'assurances, (Revue Scientifique 4 juin 1901.)

2. Trata-se de uma lei baseada no código de trabalho francês.

\section{AUTORES}

\section{ARMAND IMBERT}

Professor na Faculdade de Medicina de Montpellier

\section{ANTONIM MESTRE}

Inspector do trabalho no Departamento de Hérault 